BAREKENG: Jurnal Ilmu Matematika dan Terapan

\title{
FUNGSI ELEMEN KELAS STUMMEL MODULUS TERBATAS TETAPI BUKAN ELEMEN DARI KELAS STUMMEL
}

\section{A Function Belongs to Bounded Stummel Modulus Classes But Not in Stummel Classes}

\author{
Nicky K. Tumalun* \\ Jurusan Matematika, Fakultas Matematika dan Ilmu Pengetahuan Alam, Universitas Negeri Manado \\ Tondano Selatan, Minahasa, KP 95681, Indonesia
}

Corresponding author e-mail: 1* nickytumalun@unima.ac.id

\begin{abstract}
Abstrak
Di dalam makalah [1] diberikan contoh suatu fungsi yang mempunyai sifat sebagai elemen dari kelas Stummel modulus terbatas, tetapi bukan elemen dari kelas Stummel. Proses pembuktian sifat fungsi ini terlalu ringkas dan sulit dipahami. Dengan menggunakan sifat linearitas terhitung integral dan teknik menghitung integral melalui koordinat polar, sifat-sifat ukuran dan integral Lebesgue, dan observasi sifat-sifat geometris bola terbuka pada ruang Euclid, ditunjukkan secara detail langkah-langkah pembuktian mengenai sifat fungsi tersebut.
\end{abstract}

Kata Kunci : Kelas Stummel modulus terbatas, Kelas Stummel.

Abstract

In the paper [1], it was given a function which belongs to the bounded Stummel modulus classes but not in Stummel classes. The given proof of this function properties in that paper was not obvious and very concise. By using the countable linearity property of integral, polar coordinate of integration, other properties of Lebesgue measure and integration, and some observation on the geometric property of the open ball in Euclidean spaces, we prove in detail the properties of this function.

Keywords: Bounded Stummel modulus classes, Stummel classes. 


\section{PENDAHULUAN}

Misalkan $0<\alpha<n, 1 \leq p<\infty$, dan $f \in L_{\text {loc }}^{p}\left(\mathbb{R}^{n}\right)$, modulus Stummel (Stummel modulus) dari $f$ didefinisikan dengan

$$
\eta_{\alpha, p} f(r)=\sup _{x \in \mathbb{R}^{n}}\left(\int_{B(x, r)} \frac{|f(y)|^{p}}{|x-y|^{n-\alpha}} d y\right)^{\frac{1}{p}}, \quad r>0 .
$$

Himpunan

$$
\widetilde{S}_{\alpha, p}=\left\{f \in L_{l o c}^{p}\left(\mathbb{R}^{n}\right): \eta_{\alpha, p} f(r)<\infty, \forall r>0\right\}
$$

disebut dengan nama kelas Stummel modulus terbatas (bounded Stummel modulus classes). Himpunan

$$
S_{\alpha, p}=\left\{f \in \widetilde{S}_{\alpha, p}: \lim _{r \rightarrow 0} \eta_{\alpha, p} f(r)=0\right\}
$$

disebut dengan nama kelas Stummel (Stummel classes). Kelas Stummel akhir-akhri ini cukup menarik perhatian beberapa peneliti dalam mengkaji hubungan inklusinya dengan ruang-ruang fungsi lain dan aplikasinya dalam studi regularitas persamaan diferensial parsial eliptik [2, 3, 4, 5].

Perhatikan bahwa kelas Stummel adalah himpunan bagian dari kelas Stummel modulus terbatas, dan dalam makalah [1] telah ditunjukkan bahwa relasi himpunan bagian ini bersifat sejati, yaitu $S_{\alpha, p}$ himpunan bagian sejati dari $\widetilde{S}_{\alpha, p}$. Hal ini dikarenakan fungsi $V$ yang diberikan dalam paragraf berikut.

Misalkan $n$ bilangan asli lebih dari $2,0<\alpha<n$, dan $1 \leq p<\infty$. Untuk setiap $k$ bilangan asli lebih dari sama dengan 3 , misalkan $x_{k}=\left(2^{-k}, 0, \ldots, 0\right) \in \mathbb{R}^{n}$ dan

$$
V_{k}(y)=\left\{\begin{array}{l}
8^{\alpha k}: y \in B\left(x_{k}, 8^{-k}\right) \\
0 \quad: y \notin B\left(x_{k}, 8^{-k}\right)
\end{array}\right.
$$

Didefinisikan fungsi $V: \mathbb{R}^{n} \rightarrow \mathbb{R}$ dengan formula

$$
V(y)=\left(\sum_{k=3}^{\infty} V_{k}(y)\right)^{\frac{1}{p}} .
$$

Fungsi ini muncul dalam makalah [1, p. 552] dan merupakan contoh suatu fungsi yang merupakan elemen dari kelas Stummel modulus terbatas, tetapi bukan elemen dari kelas Stummel. Fungsi $V$ dalam makalah ini selalu merujuk pada fungsi yang didefinisikan dengan persamaan (1).

Proses pembuktian $V \in \widetilde{S}_{\alpha, p}$ tetapi $V \notin S_{\alpha, p}$ dalam makalah [1] sukar untuk dipahami, karena begitu banyak detail-detail penting yang dilewati. Tujuan dari makalah ini adalah menunjukkan secara terperinci bahwa $V \in \widetilde{S}_{\alpha, p}$ tetapi $V \notin S_{\alpha, p}$. Langkah-langkah terperinci ini merupakan hal-hal yang baru, dan sepengetahuan penulis belum pernah dipublikasikan.

\section{METODE PENELITIAN}

Metode penelitian dalam makalah ini adalah telaah pustaka. Penelitian dimulai dengan menentukan sifat-sifat, berkaitan dengan teori ukuran dan integral Lebesgue, yang dibutuhkan dalam menjawab tujuan penelitian. Kemudian, melalui sifat-sifat ini, tujuan penelitian akan dibahas secara rinci. Berikut sifat-sifat tersebut.

Misalkan $E$ himpunan bagian terukur (Lebesgue) dari $\mathbb{R}^{n}$. Notasi $|E|$ menyatakan ukuran dari himpunan $E$. Untuk setiap $x \in \mathbb{R}^{n}$ dan $r>0$, himpunan $B(x, r)=\left\{y \in \mathbb{R}^{n}:|y-x|<r\right\}$ dinamakan bola terbuka berpusat di $x$ dengan radius $r$. Ukuran dari $B(x, r)$ adalah

$$
|B(x, r)|=\omega_{n-1} \frac{r^{n}}{n}
$$


dengan $\omega_{n-1}$ adalah luas permukaan bola satuan (radius 1) di $\mathbb{R}^{n}$ (lihat [2, p. 92] untuk informasi lebih lanjut).

Untuk kepraktisan penulisan dalam makalah ini, jika variabel dari suatu fungsi terukur $f$ yang terdefinisi pada $E$ tidak penting peranannya, maka akan dituliskan

$$
\int_{E} f(y) d y=\int_{E} f
$$

Dua sifat pertama yang akan diberikan dalam bagian ini adalah sifat integral fungsi identitas [7, p. 336], dan sifat kemonotonan integral terhadap integran [7, pp. 373-374].

Proposisi 1. (Integral fungsi identitas) Jika E himpunan bagian terukur dari $\mathbb{R}^{n}$, maka

$$
\int_{E} 1=|E|
$$

Proposisi 2. (Kemonotonan integral terhadap integran) Misalkan $E$ himpunan bagian terukur dari $\mathbb{R}^{n}, f$ dan $g$ keduannya fungsi terukur yang terdefinisi pada E. Jika $f \leq g$ hampir di mana-mana pada $E$, maka

$$
\int_{E} f \leq \int_{E} g
$$

Dengan menggunakan Proposisi 1, sifat jumlahan integral terhadap domain [7, p. 374], dan Proposisi 2, diperoleh sifat kemonotonan integral terhadap domain berikut ini.

Proposisi 3. (Kemonotonan integral terhadap domain) Misalkan D dan E dua himpunan bagian terukur dari $\mathbb{R}^{n}$ dan $f$ fungsi terukur tak negatif yang terdefinisi pada $\mathbb{R}^{n}$. Jika $D \subseteq E$, maka

$$
\int_{D} f \leq \int_{E} f
$$

Salah satu fakta penting di sini adalah teknik menghitung integral dengan menggunakan koordinat polar. Untuk keperluan hal ini, diperlukan pengertian fungsi radial. Suatu fungsi terukur $f$ yang terdefinisi pada $\mathbb{R}^{n}$ disebut fungsi radial jika terdapat fungsi $h:(0, \infty) \rightarrow \mathbb{R}$ sehingga $f(y)=h(|y|)$. Teorema berikut buktinya dapat dilihat dalam [8, p. 79].

Proposisi 4. (Integral koordinat polar) Misalkan $r>0$. Jika $f$ fungsi radial dan tak negatif, maka

$$
\int_{B(0, r)} f(y) d y=\int_{B(0, r)} h(|y|) d y=\omega_{n-1} \int_{0}^{r} h(t) t^{n-1} d t .
$$

Bagian ini akan ditutup oleh sifat linearitas terhitung integral. Sifat ini berperan penting pada saat menghitung integral suatu fungsi yang didefinisikan sebagai jumlahan terhitung fungsi-fungsi terukur tak negative [7, p. 372].

Proposisi 5. (Linearitas terhitung integral) Misalkan E himpunan bagian terukur dari $\mathbb{R}^{n}$.Jika $\left\{f_{k}\right\}_{k=1}^{\infty}$ adalah barisan fungsi terukur tak negatif dan terdefinisi pada $E$, maka

$$
\int_{E} \sum_{k=1}^{\infty} f_{k}=\sum_{k=1}^{\infty} \int_{E} f_{k}
$$

\section{HASIL DAN PEMBAHASAN}

Fungsi terukur $f$ yang terdefinisi pada $\mathbb{R}^{n}$ dikatakan terintegral-p secara lokal pada $\mathbb{R}^{n}$, untuk $1 \leq$ $p<\infty$, dan ditulis $f \in L_{l o c}^{p}\left(\mathbb{R}^{n}\right)$, jika untuk setiap $x \in \mathbb{R}^{n}$ dan $r>0$, maka 


$$
\int_{B(x, r)}|f|^{p}<\infty
$$

Lema 1. Fungsi $V$ terintegral-p secara lokal pada $\mathbb{R}^{n}$, yaitu $V \in L_{l o c}^{p}\left(\mathbb{R}^{n}\right)$.

Bukti: Diberikan sembarang $x \in \mathbb{R}^{n}$ dan $r>0$. Menurut definisi $V$ dan Proposisi 5, diperoleh

$$
\int_{B(x, r)}|V(y)|^{p} d y=\int_{B(x, r)} \sum_{k=3}^{\infty} V_{k}(y) d y=\sum_{k=3}^{\infty} \int_{B(x, r)} V_{k}(y) d y .
$$

Selanjutnya, menurut definisi $V_{k}$ dan Proposisi 3,

$$
\sum_{k=3}^{\infty} \int_{B(x, r)} V_{k}(y) d y=\sum_{k=3}^{\infty} \int_{B(x, r) \cap B\left(x_{k}, 8^{-k}\right)} 8^{\alpha k} d y \leq \sum_{k=3}^{\infty} \int_{B\left(x_{k}, 8^{-k}\right)} 8^{\alpha k} d y=\sum_{k=3}^{\infty} 8^{\alpha k} \int_{B\left(x_{k}, 8^{-k}\right)} 1 d y .
$$

Proposisi 3 dapat diaplikasikan pada langkah sebelumnya karena $B(x, r) \cap B\left(x_{k}, 8^{-k}\right) \subseteq B\left(x_{k}, 8^{-k}\right)$. Menggunakan Proposisi 1, nilai dari ukuran bola, dan $\alpha-n<0$, maka

$$
\sum_{k=3}^{\infty} 8^{\alpha k} \int_{B\left(x_{k}, 8^{-k}\right)} 1 d y=\sum_{k=3}^{\infty} 8^{\alpha k} \frac{\omega_{n-1}}{n}\left(8^{-k}\right)^{n}=\frac{\omega_{n-1}}{n} \sum_{k=3}^{\infty} 8^{(\alpha-n) k}<\infty .
$$

Dengan menggabungkan semua informasi di atas, disimpulkan

$$
\int_{B(x, r)}|V(y)|^{p} d y \leq \frac{\omega_{n-1}}{n} \sum_{k=3}^{\infty} 8^{(\alpha-n) k}<\infty .
$$

Lema terbukti.

Lema 2. Misalkan $k$ bilangan asli dan $x \in \mathbb{R}^{n}$. Jika $\left|x-x_{k}\right| \geq 2\left(4^{-k}\right)$, maka

$$
\int_{B\left(x_{k}, 8^{-k}\right)} \frac{8^{\alpha k}}{|y-x|^{n-\alpha}} d y<\frac{\omega_{n-1}}{n} 2^{(\alpha-n) k} .
$$

Bukti: Diambil sembarang $y \in B\left(x_{k}, 8^{-k}\right)$, maka $\left|y-x_{k}\right|<8^{-k}$. Hal ini berarti

$$
2\left(4^{-k}\right) \leq\left|x-x_{k}\right| \leq|x-y|+\left|y-x_{k}\right|<|x-y|+8^{-k}<|x-y|+4^{-k} .
$$

Menurut ketaksamaan ini, diperoleh

$$
2\left(4^{-k}\right)<|x-y|+4^{-k} \Rightarrow 4^{-k}<|x-y| \Rightarrow 4^{-k(n-\alpha)}<|x-y|^{n-\alpha} \Rightarrow \frac{1}{|y-x|^{n-\alpha}}<4^{(n-\alpha) k} .
$$

Dengan menggunakan ketaksamaan terakhir dan Proposisi 2, akibatnya

$$
\int_{B\left(x_{k}, 8^{-k}\right)} \frac{8^{\alpha k}}{|y-x|^{n-\alpha}} d y<\int_{B\left(x_{k}, 8^{-k}\right)} 8^{\alpha k} 4^{(n-\alpha) k} d y=8^{\alpha k} 4^{(n-\alpha) k} \int_{B\left(x_{k}, 8^{-k}\right)} 1 d y .
$$

Menurut Proposisi 1 dan nilai dari ukuran bola, maka

$$
\int_{B\left(x_{k}, 8^{-k}\right)} 1 d y=\frac{\omega_{n-1}}{n} 8^{-k n}
$$

Oleh karena itu

$$
\int_{B\left(x_{k}, 8^{-k}\right)} \frac{8^{\alpha k}}{|y-x|^{n-\alpha}} d y<8^{\alpha k} 4^{(n-\alpha) k} \frac{\omega_{n-1}}{n} 8^{-k n}=\frac{\omega_{n-1}}{n} 8^{\alpha(k-n)} 4^{(n-\alpha) k}=\frac{\omega_{n-1}}{n} 2^{(\alpha-n) k} .
$$

Lema terbukti. 
Lema 3. Misalkan $k$ bilangan asli dan $x \in \mathbb{R}^{n}$. Jika $\left|x-x_{k}\right|<2\left(4^{-k}\right)$, maka

$$
\int_{B\left(x_{k}, 8^{-k}\right)} \frac{8^{\alpha k}}{|y-x|^{n-\alpha}} d y \leq \omega_{n-1} \frac{3^{\alpha}}{\alpha}
$$

Bukti: Karena $\left|x-x_{k}\right|<2\left(4^{-k}\right)$, maka terdapat dua kemungkinan, pertama $2\left(8^{-k}\right) \leq\left|x-x_{k}\right|<2\left(4^{-k}\right)$, atau, kedua $\left|x-x_{k}\right|<2\left(8^{-k}\right)$. Untuk kemungkinan pertama, diambil sembarang $y \in B\left(x_{k}, 8^{-k}\right)$, diperoleh

$$
2\left(8^{-k}\right) \leq\left|x-x_{k}\right| \leq|x-y|+\left|y-x_{k}\right|<|x-y|+8^{-k},
$$

yang berakibat $8^{-k}<|x-y|$. Selanjutnya diperoleh

$$
\frac{1}{|x-y|^{n-\alpha}}<8^{(n-\alpha) k}
$$

Dengan demikian

$$
\begin{aligned}
\int_{B\left(x_{k}, 8^{-k}\right)} \frac{8^{\alpha k}}{|y-x|^{n-\alpha}} d y & \leq \int_{B\left(x_{k}, 8^{-k}\right)} 8^{\alpha k} 8^{(n-\alpha) k} d y=8^{n k} \int_{B\left(x_{k}, 8^{-k}\right)} 1 d y \\
& =8^{n k} \frac{\omega_{n-1}}{n} 8^{-n k}=\frac{\omega_{n-1}}{n}<\omega_{n-1} \frac{3^{\alpha}}{\alpha} .
\end{aligned}
$$

Untuk kemungkinan kedua, diambil sembarang $y \in B\left(x_{k}, 8^{-k}\right)$. Karena $\left|x-x_{k}\right|<2\left(8^{-k}\right)$, maka

$$
|y-x| \leq\left|y-x_{k}\right|+\left|x_{k}-x\right|<3\left(8^{-k}\right),
$$

yang berarti $y \in B\left(x, 3\left(8^{-k}\right)\right)$. Hal ini berarti $B\left(x_{k}, 8^{-k}\right) \subseteq B\left(x, 3\left(8^{-k}\right)\right)$. Menurut Proposisi 3, diperoleh

$$
\int_{B\left(x_{k}, 8^{-k}\right)} \frac{8^{\alpha k}}{|y-x|^{n-\alpha}} d y \leq \int_{B\left(x, 3\left(8^{-k}\right)\right)} \frac{8^{\alpha k}}{|y-x|^{n-\alpha}} d y=\int_{B\left(0,3\left(8^{-k}\right)\right)} \frac{8^{\alpha k}}{|z|^{n-\alpha}} d z .
$$

Dengan menggunakan Proposisi 4,

$$
\int_{B\left(0,3\left(8^{-k}\right)\right)} \frac{8^{\alpha k}}{|z|^{n-\alpha}} d z=\omega_{n-1} 8^{\alpha k} \int_{0}^{3\left(8^{-k}\right)} \frac{1}{t^{n-\alpha}} t^{n-1} d t=\omega_{n-1} 8^{\alpha k} \int_{0}^{3\left(8^{-k}\right)} t^{\alpha-1} d t=\omega_{n-1} \frac{3^{\alpha}}{\alpha}
$$

Oleh karena itu

$$
\int_{B\left(x_{k}, 8^{-k}\right)} \frac{8^{\alpha k}}{|y-x|^{n-\alpha}} d y \leq \omega_{n-1} \frac{3^{\alpha}}{\alpha} .
$$

Berdasarkan kedua kemungkinan yang sudah diperiksa, lema terbukti.

Fakta sederhana berikut ini dapat dibuktikan dengan prinsip induksi matematika dan digunakan dalam membuktikan lema di bawah ini. Untuk setiap $i$ bilangan asli, berlaku $2^{i}>2^{i-2}+5 / 4$.

Lema 4. Misalkan $k$ bilangan asli lebih dari sama dengan 3. Jika $x_{k}=\left(2^{-k}, 0, \ldots, 0\right) \in \mathbb{R}^{n}$, maka koleksi bola-bola terbuka $\left\{B\left(x_{k}, 2\left(4^{-k}\right)\right)\right\}_{k \geq 3}^{\infty}$ adalah koleksi himpunan saling asing.

Bukti: Misalkan $j, k$ keduanya bilangan asli lebih besar sama dengan 3 , dengan $j \neq k$. Asumsikan $j<k$. Diperoleh, terdapat bilangan asli $i$ sehingga $j+i=k$. Akan dibuktikan $B\left(x_{j}, 2\left(4^{-j}\right)\right) \cap B\left(x_{k}, 2\left(4^{-k}\right)\right)=$ $\emptyset$. Bukti secara kontradiksi. Andaikan $B\left(x_{j}, 2\left(4^{-j}\right)\right) \cap B\left(x_{k}, 2\left(4^{-k}\right)\right) \neq \emptyset$. Berarti, terdapat $y \in \mathbb{R}^{n}$ sehingga $\left|y-x_{j}\right|<2\left(4^{-j}\right)$ dan $\left|y-x_{k}\right|<2\left(4^{-k}\right)$. Diperhatikan bahwa

$$
\frac{2^{i}-1}{2^{k}}=2^{-j}-2^{-k}=\left|x_{j}-x_{k}\right| \leq\left|x_{j}-y\right|+\left|y-x_{k}\right|<2\left(4^{-j}\right)+2\left(4^{-k}\right)=\frac{2\left(4^{i}\right)+2}{4^{k}} .
$$


Oleh karena itu

$$
2^{i}-1<2^{k}\left(\frac{2\left(4^{i}\right)+2}{4^{k}}\right)=\frac{2\left(4^{i}\right)+2}{2^{k}} \leq 2^{i-j+1}+\frac{1}{4}
$$

Akibatnya

$$
2^{i}<2^{i-j+1}+\frac{5}{4} \leq 2^{i-2}+\frac{5}{4}
$$

Ketaksamaan ini berkontradiksi dengan fakta $2^{i}>2^{i-2}+5 / 4$, untuk setiap bilangan asli $i$. Dengan demikian, lema terbukti secara kontradiksi.

Teorema pertama di bawah ini adalah akibat dari Lema 2 dan Lema 3.

Teorema 1. Jika $x \in \mathbb{R}^{n}$, maka

$$
\int_{\mathbb{R}^{n}} \frac{|V(y)|^{p}}{|x-y|^{n-\alpha}} d y \leq C(n, \alpha)<\infty,
$$

dengan

$$
C(n, \alpha)=\max \left\{\frac{\omega_{n-1}}{n} \sum_{k=3}^{\infty} 2^{(\alpha-n) k}, \omega_{n-1} \frac{3^{\alpha}}{\alpha}+\frac{\omega_{n-1}}{n} \sum_{\substack{k=3 \\ k \neq j}}^{\infty} 2^{(\alpha-n) k}\right\}
$$

Bukti: Menurut definisi $V$ dan Proposisi 5, diperoleh

$$
\int_{\mathbb{R}^{n}} \frac{|V(y)|^{p}}{|x-y|^{n-\alpha}} d y=\sum_{k=3}^{\infty} \int_{\mathbb{R}^{n}} \frac{V_{k}(y)}{|x-y|^{n-\alpha}} d y=\sum_{k=3}^{\infty} \int_{B\left(x_{k}, 8^{-k}\right)} \frac{8^{\alpha k}}{|y-x|^{n-\alpha}} d y .
$$

Karena $x \in \mathbb{R}^{n}$, maka terdapat dua kasus, $x \notin \cup_{k=3}^{\infty} B\left(x_{k}, 2\left(4^{-k}\right)\right)$, atau, $x \in \cup_{k=3}^{\infty} B\left(x_{k}, 2\left(4^{-k}\right)\right)$. Untuk kasus pertama, diperoleh $\left|x-x_{k}\right| \geq 2\left(4^{-k}\right)$ untuk setiap $k \geq 3$, dan

$$
\sum_{k=3}^{\infty} \int_{B\left(x_{k}, 8^{-k}\right)} \frac{8^{\alpha k}}{|y-x|^{n-\alpha}} d y \leq \frac{\omega_{n-1}}{n} \sum_{k=3}^{\infty} 2^{(\alpha-n) k}<\infty,
$$

dengan menggunakan Lema 2 dan $\alpha-n<0$. Untuk kasus kedua, maka menurut Lema 4 , terdapat tepat satu bilangan asli $j$ dengan $j \geq 3$, sehingga $x \in B\left(x_{j}, 2\left(4^{-j}\right)\right)$ dan $x \notin B\left(x_{k}, 2\left(4^{-k}\right)\right)$, untuk setiap $k \geq 3$ dengan $k \neq j$. Karena $\left|x-x_{j}\right|<2\left(4^{-j}\right)$, maka

$$
\int_{B\left(x_{j}, 8^{-j}\right)} \frac{8^{\alpha j}}{|y-x|^{n-\alpha}} d y \leq \omega_{n-1} \frac{3^{\alpha}}{\alpha}
$$

menurut Lema 3. Selanjutnya, karena $\left|x-x_{k}\right| \geq 2\left(4^{-k}\right)$ untuk setiap $k \geq 3$ dengan $k \neq j$, maka menurut Lema 2,

$$
\int_{B\left(x_{k}, 8^{-k}\right)} \frac{8^{\alpha k}}{|y-x|^{n-\alpha}} d y \leq \frac{\omega_{n-1}}{n} 2^{(\alpha-n) k}
$$

Akibatnya

$$
\sum_{k=3}^{\infty} \int_{B\left(x_{k}, 8^{-k}\right)} \frac{8^{\alpha k}}{|y-x|^{n-\alpha}} d y=\int_{B\left(x_{j}, 8^{-j}\right)} \frac{8^{\alpha j}}{|y-x|^{n-\alpha}} d y+\sum_{\substack{k=3 \\ k \neq j}}^{\infty} \int_{B\left(x_{k}, 8^{-k}\right)} \frac{8^{\alpha k}}{|y-x|^{n-\alpha}} d y
$$




$$
\leq \omega_{n-1} \frac{3^{\alpha}}{\alpha}+\frac{\omega_{n-1}}{n} \sum_{\substack{k=3 \\ k \neq j}}^{\infty} 2^{(\alpha-n) k}<\infty
$$

Berdasarkan kedua kasus di atas,

$$
\begin{aligned}
& \int_{\mathbb{R}^{n}} \frac{|V(y)|^{p}}{|x-y|^{n-\alpha}} d y=\sum_{k=3}^{\infty} \int_{B\left(x_{k}, 8^{-k}\right)} \frac{8^{\alpha k}}{|y-x|^{n-\alpha}} d y \\
& \quad \leq \max \left\{\frac{\omega_{n-1}}{n} \sum_{k=3}^{\infty} 2^{(\alpha-n) k}, \omega_{n-1} \frac{3^{\alpha}}{\alpha}+\frac{\omega_{n-1}}{n} \sum_{\substack{k=3 \\
k \neq j}}^{\infty} 2^{(\alpha-n) k}\right\} .
\end{aligned}
$$

Lema terbukti.

Teorema 1 dan Lema 1 memberikan akibat berikut ini.

Akibat 1. $V \in \widetilde{S}_{\alpha, p}$.

Bukti: Menurut Lema $1, V \in L_{l o c}^{p}\left(\mathbb{R}^{n}\right)$. Diberikan sembarang $x \in \mathbb{R}^{n}$ dan $r>0$. Menurut Proposisi 3 dan Teorema 1, diperoleh

$$
\int_{B(x, r)} \frac{|V(y)|^{p}}{|x-y|^{n-\alpha}} d y \leq \int_{\mathbb{R}^{n}} \frac{|V(y)|^{p}}{|x-y|^{n-\alpha}} d y=C(n, \alpha)<\infty .
$$

Karena ketaksamaan terakhir berlaku untuk setiap $x \in \mathbb{R}^{n}$, yang tidak bergantung dari $C(n, \alpha)$, maka

$$
\eta_{\alpha, p} V(r)=\sup _{x \in \mathbb{R}^{n}}\left(\int_{B(x, r)} \frac{|V(y)|^{p}}{|x-y|^{n-\alpha}} d y\right)^{\frac{1}{p}} \leq C(n, \alpha)^{\frac{1}{p}}<\infty .
$$

Akibat terbukti.

Untuk membuktikan fungsi $V$ bukan elemen dari $S_{\alpha, p}$, harus ditunjukkan bahwa modulus Stummel dari $V$ tidak konvergen ke 0 , apabila radius bola konvergen 0 . Berikut buktinya.

Teorema 2. $V \notin S_{\alpha, p}$.

Bukti: Diberikan sembarang $r>0$. Menurut sifat Archimedes, terdapat bilangan asli $k \geq 3$, sehingga $8^{-k}<$ $r$. Hal ini berarti $B\left(x_{k}, 8^{-k}\right) \subseteq B\left(x_{k}, r\right)$. Oleh karena itu, dengan menggunakan Proposisi 2, Proposisi 3, dan kemudian Proposisi 4, diperoleh

$$
\begin{aligned}
\int_{B\left(x_{k}, r\right)} \frac{|V(y)|^{p}}{\left|x_{k}-y\right|^{n-\alpha}} d y & \geq \int_{B\left(x_{k}, r\right)} \frac{V_{k}(y)}{\left|x_{k}-y\right|^{n-\alpha}} d y \geq \int_{B\left(x_{k}, 8^{-k}\right)} \frac{V_{k}(y)}{\left|x_{k}-y\right|^{n-\alpha}} d y \\
& =\int_{B\left(x_{k}, 8^{-k}\right)} \frac{8^{\alpha k}}{\left|x_{k}-y\right|^{n-\alpha}} d y=8^{\alpha k} \frac{\omega_{n-1}}{\alpha} 8^{-\alpha k}=\frac{\omega_{n-1}}{\alpha} .
\end{aligned}
$$

Menurut ketaksamaan ini dan pengertian modulus Stummel, akibatnya

$$
\eta_{\alpha, p} V(r) \geq\left(\int_{B(x, r)} \frac{|V(y)|^{p}}{|x-y|^{n-\alpha}} d y\right)^{\frac{1}{p}} \geq\left(\frac{\omega_{n-1}}{\alpha}\right)^{\frac{1}{p}}>0 .
$$

Dengan demikian

$$
\lim _{r \rightarrow 0} \eta_{\alpha, p} V(r) \geq\left(\frac{\omega_{n-1}}{\alpha}\right)^{\frac{1}{p}}>0
$$


Disimpulkan bahwa $V \notin S_{\alpha, p}$.

\section{KESIMPULAN}

Kelas Stummel merupakan himpunan bagian dari kelas Stummel modulus terbatas. Hubungan inklusi ini (relasi himpunan bagian), bersifat sejati. Hal ini dikarenakan, terdapat fungsi $V$ sebagai elemen dari kelas Stummel modulus terbatas, tetapi bukan elemen dari kelas Stummel. Proses pembuktian sifat fungsi $V$ ini memerlukan pengetahuan mengenai sifat-sifat integral Lebesgue dan sifat integral fungsi radial dalam koordinat polar.

\section{DAFTAR PUSTAKA}

[1] N. K. Tumalun, D. I. Hakim and H. Gunawan, "Inclusion between generalized Stummel classes and other function spaces," Math. Inequal. Appl., vol. 23, no. 2, pp. 547-562, 2020.

[2] N. K. Tumalun, H. Gunawan and J. Lindiarni, "On the inclusion between weak Lebesgue spaces and Stummel classes," in 5th ICRIEMS, Yogyakarta, 2018

[3] N. K. Tumalun and H. Gunawan, "Morrey spaces are embedded between weak Morrey spaces and Stummel classes," J. Indones. Math. Soc., vol. 25, no. 3, pp. 203-209, 2019.

[4] G. Di Fazio, M. S. Fanciullo and P. Zamboni, "Regularity up to the boundary for some degenerate elliptic operators," Applicable Analysis, pp. 1-13, 2020.

[5] S. Samko, "Morrey spaces are closely embedded between vanishing Stummel class," Math. Ineq. Appl., vol. 17, no. 2, pp. 627639, 2014.

[6] E. M. Stein and S. Sharkarchi, Real Analysis: Measure Theory, Integration, and Hilbert Spaces, New Jersey: Princenton University Press, 2005.

[7] H. L. Royden and P. M. Fitzpatrick, Real Analysis. Fourth Edition, Boston: Prentice Hall, 2010.

[8] G. B. Folland, Real Analysis: Modern Techniques and Their Applications. Second Edition, New York: John Willey and Sons, Inc., 1999. 